\title{
EFFECTS OF DISTANCE AND FIRST-TIME VISITATION \\ ON TOURISTS' LENGTH OF STAY
}

\author{
Juan L. Nicoloau \\ University of Alicante \\ Florian J. Zach, Iis P. Tussyadiah \\ Washington State University
}

\begin{abstract}
The analysis of length of stay and its determinants remains important in tourism due to its significant implications for tourism management. Results from previous studies show conflicting effects of the two central factors of length of stay: distance and first-time visitation. Hence, taking into account the not-always-unambiguous effect of distance and the variety-seeking and inertial behaviors of repeat visitation, the objective of this research is to add to the extant literature further empirical evidence. Data were collected from 908 US visitors to a tourism destination in the Atlantic Coast of the United States and analyzed using the Truncated Negative Binomial models. A positive impact of both distance and first-time visitation on length of stay is found. Managerial implications are provided.
\end{abstract}

Keywords: length of stay; distance; first-time visitor; Truncated Negative Binomial Model

Cite as: Nicolau, J. L., Zach, F. J., \& Tussyadiah, I. P. (2016). Effects Of Distance And First-Time Visitation On Tourists' Length Of Stay. Journal of Hospitality \& Tourism Research. doi:10.1177/1096348016654972 


\section{EFFECTS OF DISTANCE AND FIRST-TIME VISITATION \\ ON TOURISTS' LENGTH OF STAY}

\section{INTRODUCTION}

The duration of vacation is of paramount importance for tourism destinations and hospitality businesses due to its significant implications for tourism planning and management (Alegre \& Pou, 2006; Barros \& Machado, 2010; Grigolonet, Borgers, Kemperman, \& Timmermans, 2014; Martínez-Garcia \& Raya, 2008). First of all, length

of stay is a key variable of tourism demand. The temporal decision of the duration of stay ultimately represents the "quantity of holiday" bought by the tourist (Mak \& Moncur, 1979) and, hence, the income generated for tourism destinations (Agarwal \& Yochum, 1999; Allegre \& Pou, 2006; Cannon \& Ford, 2002). Indeed, previous studies emphasize the point that the income received at a destination depends mainly on the number of tourists and the number of days they spend there (Alegre \& Pou, 2006; Barros \& Machado, 2010; Barros, Butler, \& Correa, 2010). Consequently, length of stay is considered an operational variable to partition tourists when implementing segmentation strategies (Pullman \& Rodgers, 2010) and is critical to assess the revenue value of a tourist (Wang, 2012). Therefore, an extensive knowledge of the determinants of length of stay allows tourism destinations to define their strategies in order to increase aggregate earnings by attracting a greater number of tourists with a high level of per-day expenditures or promoting longer stays.

Furthermore, length of stay has a direct impact on tourists' activities and behavior. The social interactions among tourists and between tourists and local residents are contingent upon the time spent in the destination. Previous studies suggest the links between length of stay and intensity of tourist-host interactions as well as degree of 
participation in tourism activities (Aissa and Goaied, 2014; Lau \& McKercher, 2004; Lew \& McKercher, 2004), which lead to satisfaction, positive attitude, and favorable image of the destinations (e.g., Fakeye \& Crompton, 1991). Previous studies also show that length of stay is highly associated with the range of activities taken while on vacation and spatial movement patterns in the destinations (Barros \& Machado, 2010; Lew \& McKercher, 2004). For example, tourists with shorter stays typically stay centrally and visit only the major attractions, while those who stay longer tend to enjoy a greater range of activities and attractions and explore more peripheral regions (Barros \& Machado, 2010). That is to say, as length of stay implies various economic, social, and environmental impacts, it presents a critical policy implication for tourism destinations. Consequently, understanding the factors that contribute to tourists' decisions on length of stay will inform policy makers in the estimation, planning, and management of tourism impacts.

Previous studies suggest various factors that result in differences in the duration of stay, which include tourists' profile (e.g., age, occupation, nationality, income, etc.), destination characteristics (e.g., beach vs. heritage destinations), as well as trip characteristics (e.g., purposes of trips, tour packages, transportation modes). Similarly, different motives for travel were found to result in different length of stay (Correia, Silva \& Moço, 2008). Among the different variables that have been proven to have an influence on length of stay, distance (e.g., Bell \& Leeworthy, 1990; Silberman, 1985) and first-time vs. repeat visitation (e.g., Lau \& McKercher, 2004; Opperman, 1997) are considered essential, but result in contrasting effects. Indeed, the literature shows little consensus about the effects of these two variables on length of stay, with various research findings indicating both positive and negative effects. Changes in travel behavior (e.g. multiple shorter vacations per year), changes in the market place (e.g. low 
cost airlines in Europe or the Internet) and negative effects of the great recession (e.g. higher unemployment rates) result in a progressive decline in overall length of stay in recent years. As such, it is important to shed some light on these conflicting effects in order to better understand the factors of length of stay that contribute to the competitive strategies for tourism destinations. Accordingly, in the literature review we have considered the not-always-unambiguous effect of distance and the variety-seeking and inertial behaviors of repeat visitation to justify the objective of this article and to show the relevance of the examination of distance and first-time visits and their effects on length of stay. To that end, this study investigates the length of stay of visitors to a drive tourism destination on the Atlantic Coast of the United States. This will provide a comparison to the most recent studies investigating the causal relationships between determinants and length of stay in European summer destinations that differ to the United States in terms of travel behavior, availability of true budget airlines, and different types of accommodation.

\section{DETERMINANTS OF LENGTH OF STAY}

\subsection{Distance}

Distance is an attribute that all tourists have to overcome (or enjoy) to get satisfaction from tourism destinations. The distance between tourists' origin and a destination is especially important due to the marked spatial dimension inherent in tourism (i.e., tourism requires movement from one place to another). Certainly, the spatial configuration of tourism consumption makes distance a key attribute of tourism demand (Adamowicz, Louviere, \& Williams, 1994; Barros, Butler, \& Correa, 2008; Borgers, Van der Hejden, \& Timmermans, 1989; Fesenmaier, 1988; Moutinho \& Trimble, 1991; Perdue, 1986; Schroeder \& Louviere, 1999; Stopher \& Ergün, 1979; Wennergren \& Nielsen, 1968). The traditional research perspective holds that distance (i.e., a tourist's 
geographical position relative to a destination) is a restriction or dissuasive variable of destination choice, as the displacement of a tourist entails physical, temporal, and financial effort (Taylor \& Knudson, 1976). In other words, distance is considered a factor that reduces utility. Following this approach, Silberman (1985) suggests that, at the example of Virginia Beach as a drive tourism destination (compared to Aspen as a flight destination), as distance between origins and destinations increases, length of stay will increase. This is due to the fact that travel costs are fixed and independent of the number of days spent at the destination, which implies that longer stays allow tourists to spread these fixed costs over a longer period. Specifically, tourists will be prepared to make a long journey if they stay at the destination for at least the minimum number of days, which will compensate for the effort made in the journey. Therefore, greater distances should lead to longer stays. Indeed, Paul and Rimmawi (1992) as well as Blaine, Mohammad, and Var (1993) confirm the significant positive relationship between distance and duration of stay (i.e., the greater the distance, the longer the duration of stay).

However, the argument that distance always exerts a negative effect on tourism demand could not be universally valid. While longer distances represent a deterrent factor to a group of tourists, traveling to faraway destinations can be an attraction factor for another (or at least not as strong a deterrent). For example, a tourist could be willing to visit an exotic destination even though it implies traveling overseas. To this end, Baxter (1980) shows that, as a component of the tourism product, the journey itself can give satisfaction in its own right. On occasions, especially in cases of (self-) drive tourism (Prideaux \& Carson, 2003; Prideaux, Wei, \& Ruys, 2001) or train rides (Larsen, 2011), longer distances are preferred. That is, an individual may choose a long-distance car or train journey over a quicker journey by air to the same faraway destination, 
because of the opportunity to see and stop at several places on the way to the destination and enjoy the moving touristic landscape (Larsen, 2011; Zillinger, 2007). Increased distance travelled can also be a requirement for increased satisfaction; for example, bird watching requires travel to further destinations to find new species (Mark, 1981). As such, Wolfe $(1970 ; 1972)$ indicates that distance does not always act as a dissuasive factor, as the friction derived from it disappears after passing a certain threshold and it becomes a favorable attribute of the utility of a destination. Beaman $(1974 ; 1976)$ explains this behavior through a marginal analysis of distance, by observing the reaction of individuals to each unit of distance and concluding that each additional unit traveled offers less resistance than the previous. Accordingly, distance could have a neutral effect on the length of stay as some individuals could be willing to travel a long distance to visit a destination independently of the their length of stay if they enjoy the trip itself. Therefore, the following hypothesis is suggested:

H.1. Distance has an effect on length of stay.

\subsection{First-Time vs. Repeat Visitors}

Travelers' desire to discover new places plays an important role for tourism destination development. Studies found that novelty seeking behavior has a positive effect on intention to travel to explore new places and events (Jang, Bai, Hu \& Wu, 2009; Rittichainuwat, Qu \& Leong, 2003). In his seminal work, Rugg (1973) assumes that a stay in a destination over a period of time allows for the consumption or enjoyment of the attributes of the destination (p.65) and that the tourist obtains utility from this. Consequently, we can expect that people who choose a destination for a specific attribute might have a greater propensity to stay longer if they receive this attribute in return. Essentially, some tourists might prefer to stay longer because they are more likely to uncover more aspects of a destination. Xie, Kerstetter, and Mattila (2012) 
indicate that first-time visitors tend to have a higher level desire to explore new destinations than repeat visitors. Certainly, elements such as the "Ulysses Factor" proposed by Anderson (1970) can influence the tourists' length of stay. That is, if tourists are seeking for new destinations, they might be willing to stay longer to explore these destinations in greater details. Consequently, we state that:

H.2. First-time visits have a positive effect on length of stay.

Interestingly, the relationship between first-time (or repeat) visitors with their length of stay is not without ambiguities. While Thrane (2012) shows that first-time visitors are associated with longer stays, Lehto et al. (2004), Alegre and Pou (2006), Menezes, Moniz, and Vieira (2008), Barros and Machado (2010), Alegre, Mateo, and Pou (2011), and Wang, Little, and DelHomme-Little (2012) find that repeat visitors stay for longer periods. Even though they do not provide a clear-cut justification, familiarity with the destination seems to be the cause that leads to longer stays. Indeed, several studies suggest that while first-time visitors are motivated to explore (i.e., driven by curiosity), repeat visitors are more motivated to consume and participate in social activities (e.g., shop, dine, spend time with families), which indicate familiarity and lead to a longer stay (Lau \& McKercher, 2004; Lew \& McKercher, 2004). Other explanations for the contrasting effects of first-time vs. repeat visits on length of stay are associated with the tourists' profiles. For example, Oppermann (1997) finds that the positive and negative relationships between repeat visitation and length of stay depend on the origin of the tourist (i.e., nationality). Additionally, as indicated by Tse and Crotts (2005), curiosity varies between individuals. Hence, it is important to note that people's predisposition to explore unknown environments and, consequently, the time period immersed in them, depends on how secure they feel to enjoy a new destination. 
Furthermore, tourists' variety-seeking and inertial behaviors also play a role in explaining the effects of repeat visitation on length of stay (Chintagunta, 1998). Variety-seeking behavior implies that the probability of visiting a destination for vacation diminishes when it was visited previously. This is due to the probability reduction through satiation with the destination attributes. As tourists obtain utility from visiting a destination, specifically from the destination attributes (Rugg, 1973), when they reach a certain level of consumption, they become satiated with the destination and attempt to choose an alternative destination on the next vacation. For variety-seeking tourists, the motivation to discover new places might lead them to exploit the first visit at a maximum level, which means staying longer at the destination, and then visit a different destination on the next vacation. On the other hand, inertial behavior means that the visit to a destination increases the probability of choosing the same destination on the next vacation. That is, the more tourists visit a destination, the more they develop liking or positive attitudes towards the destination, and the more likely they are to repeat the visit. For example, the relaxation obtained by individuals from the climate and tranquility of a destination can lead them to revisit the same destination (Alegre \& Juaneda, 2006). Therefore, the following hypothesis is stated:

H.3. Repeat visits have a positive effect on length of stay.

\subsection{Control variable: accommodation types}

A major cost component, which usually accounts for one of the largest shares of the tourists' budget, is accommodation. Even though longer stays allow tourists to spread the fixed costs of the journey over a longer period, they still need to consider the perday costs incurred at the destination. Gokovali, Bahar and Kozak (2007) found that length of stay of summer visitors to Turkey decreased as the spending per day increased. Taking the accommodation costs into account, it can be suggested that the 
longer the stay, the larger the total trip cost. In addition to the cost of accommodation, type of accommodation itself can have an effect on the length of stay. Past studies identified the effect of accommodation costs on temporal choice (Alegre \& Pou, 2006; Barros et al., 2010; Ferrer-Rosell, Martínez-Garcia, \& Coenders, 2014; Martínez-Garcia \& Raya, 2008; 2009; Salmasi, Celidoni, \& Precidano, 2012; Silberman, 1985). Specifically, these studies suggest that, on the account of the total costs involved during the stay, hotel accommodation, due to its higher cost, is associated with shorter stays compared to other types of accommodation. With this in mind, the types of accommodation with lower costs per person per night, both commercial (e.g., rented apartments) and private (e.g., friend/family's houses), implies longer stays, while more expensive accommodation types such as hotels are linked to shorter stays. Indeed, Gokovali, Bahar and Kozak (2007), in their study of summer visitors to Turkey, found that visitors staying on yachts have shorter stays than those in apartments to maximize their consumer utility (i.e. length of stay). Therefore, the type of accommodation can have an effect on length of stay.

\section{RESEARCH DESIGN}

\subsection{Method}

The impacts of distance and first-time visitation on length of stay were examined with the estimation of count models. The most well-known approximation of length of stay is derived from the Poisson distribution $P(\lambda)$, where $\lambda$ is the average of the random variable, which, in this case, is the number of days spent in a destination in a certain period of time. However, this model is based on the assumption of average-variance equality, which is too restrictive to represent the behavior of individuals as it cannot consider the heterogeneity of these individuals and creates what is known as the “problem of over-dispersion” (Gurmu \& Trivedi, 1996). As an alternative, Nicolau and 
Mas (2006) propose the use of a count data model based on a Negative Binomial distribution (Cameron \& Trivedi, 1998) in order to ease the restrictions of the Poisson modeling. Following the general formulation of the Negative Binomial model, the probability of individual $t$ choosing a number $y_{t}$ of days of vacation away from the usual place of residence is given by the expression:

$$
P\left(y_{t}\right)=\frac{\Gamma\left(\alpha^{-1}+y_{t}\right)}{\Gamma\left(\alpha^{-1}\right) \Gamma\left(y_{t}+1\right)}\left(\frac{\alpha^{-1}}{\alpha^{-1}+e^{\sum_{k=1}^{K} \beta_{k} x_{t k}}}\right)^{\alpha^{-1}}\left(\frac{e^{\sum_{k=1}^{K} \beta_{k} x_{t k}}}{\alpha^{-1}+e^{\sum_{k=1}^{K} \beta_{k} x_{t k}}}\right)^{y_{t}} \forall y_{t}=\{0,1,2, \ldots\}
$$

where $\Gamma$ represents the Gamma function, $x_{t k}$ the characteristic $k$ of individual $t$ and $\beta_{k}$ the parameter which indicates the effect of $x_{t k}$ on $P\left(y_{t}\right)$. The parameter $\alpha$ covers the dispersion of the observations, in such a way that

$$
\begin{gathered}
E\left(y_{t}\right)=e^{\sum_{k=1}^{K} \beta_{k} x_{k k}}=\lambda_{t} \\
\text { and } \\
V\left(y_{t}\right)=e^{\sum_{k=1}^{K} \beta_{k} x_{k k}}+\alpha \cdot e^{2 \sum_{k=1}^{K} \beta_{k} x_{k k}}=\lambda_{t}+\alpha \cdot \lambda_{t}^{2} .
\end{gathered}
$$

One way of verifying the validity of the Negative Binomial model as opposed to the Poisson model consists of testing the null hypothesis $\alpha=0$. Note that its acceptance would imply that $E\left(y_{t}\right)=V\left(y_{t}\right)$, so that the Poisson model is a particular case of the Negative Binomial when $\alpha=0$ (Gurmu \& Trivedi, 1996). This approximation overcomes the bias problems of the regression analysis arising from the discrete character of the dependent variable (Hellerstein \& Mendelsohn, 1993); in fact, regression analysis assumes the use of a normally-distributed dependent variable, and length of stay does not follow a normal distribution. It also overcomes the inefficiency problems of the Multinomial Logit Model (Cameron \& Trivedi, 1998) when analyzing the number of days a tourist spends outside the usual place of residence. The Multinomial Logit Model 
has serious disadvantages as a consequence of the consideration of a high number of alternatives $(0,1,2,3, \ldots$ days $)$, which impedes the attainment of efficient estimations. In fact, Cameron and Trivedi (1998) indicate that alternatives should be aggregated in order to obtain an efficient estimation of the Multinomial Logit. For example, Alegre and Pou (2006) follow this approach and transform the length of stay into a discrete variable by taking weekly periods. Still, this aggregation would lead to a loss of information as the analyst would not be considering all the alternatives available to the tourist ${ }^{1}$.

According to this justification, in line with Nicolau and Mas (2006) and Alegre et al. (2011), this article uses a count data model. In particular, the adaptation of the Negative Binomial model to the situation in this study requires an additional modification, given that a zero value of the dependent variable has a qualitative meaning, which is different from that of other values. Any value above zero indicates the number of days a tourist has decided to stay at the destination, bearing in mind that the decision to go has already been made. On the other hand, a value of zero represents the qualitative decision not to go. In these types of situation, it makes sense to concentrate on those observations whose dependent variable is distinct from zero, therefore truncating the distribution of the variable (Greene, 2008). Because of all this, this study applies the model based on the Negative Binomial distribution to the sample truncated at zero. Taking these into account and following Cameron and Trivedi (1998), the expression that represents the probability of individual $t$ choosing a number $y_{t}$ of days more than zero, takes the following form:

\footnotetext{
${ }^{1}$ Beyond these models, the literature shows different alternative approaches to the analysis of length of stay: survival models have been employed by Martínez-Garcia and Raya (2008), Raya, (2012) and Raya and Martínez-Garcia (2011), mixture models by Alegre et al. (2011), quantile regression by Salmasi et al. (2012), and the ordered logit model by Ferrer-Rosell et al. (2014).
} 
$P\left(y_{t} \mid y_{t}>0\right)=\frac{\Gamma\left(\alpha^{-1}+y_{t}\right)}{\Gamma\left(\alpha^{-1}\right) \Gamma\left(y_{t}+1\right)}\left(\frac{\alpha^{-1}}{\alpha^{-1}+e^{\sum_{k=1}^{K} \beta_{k} x_{t k}}}\right)^{\alpha^{-1}}\left(\frac{e^{\sum_{k=1}^{K} \beta_{k} x_{t k}}}{\alpha^{-1}+e^{\sum_{k=1}^{K} \beta_{k} x_{t k}}}\right)^{y_{t}}\left(\frac{1}{1-\left(1+\alpha \cdot e^{\sum_{k=1}^{K} \beta_{k} x_{t k}}\right)^{\alpha^{-1}}}\right)$ $\forall y_{t}=\{1,2, \ldots\}$.

where $\beta_{k}$ is the parameter which indicates the effect of $x_{t k}$ on $P\left(y_{t} \mid y_{t}>0\right)$.

The estimation of $\theta\left(\beta_{k}\right)$ is carried out by maximum likelihood, whose function is

$$
\begin{aligned}
M L(\theta)=\sum_{t=1}^{T}\left\{\sum_{j=0}^{y_{t}-1} \ln (j\right. & \left.+\alpha^{-1}\right)-\ln \left(y_{t} !\right)-\left(y_{t}+\alpha^{-1}\right) \ln \left(1+\alpha \cdot e^{\sum_{k=1}^{K} \beta_{k} x_{t k}}\right)+ \\
& \left.+y_{t} \ln \alpha+y_{t} e^{\sum_{k=1}^{K} \beta_{k} x_{t k}}-\ln \left(1-\left(1+\alpha \cdot e^{\sum_{k=1}^{K} \beta_{k} x_{t k}}\right)^{\alpha^{-1}}\right)\right\}
\end{aligned}
$$

\subsection{Variables}

In order to make the proposed Truncated Negative Binomial model operative, the following variables are defined:

1. Dependent Variable: Length of stay. To represent the temporal demand, we obtain information on the length of stay with a quantitative variable of the number of days that a visitor spends outside the usual place of residence, in line with Mak and Moncur (1979) and Silberman (1985).

2. Independent Variables: a) Distance between origin and destination. In accordance with the literature of choice in tourism, we use the physical separation in thousands of miles between the place of origin and the chosen destination (Wennergren \& Nielsen, 1968; Fesenmaier, 1988). This information on distances between origins and destinations is calculated as the distance between US Postal Zip Codes. b) Firsttime vs. repeat visitor. We use categorical variables to collect information on the people's visitation pattern over the last three years, from where we identify the first visit ever to the destination, in line with Alegre and Pou (2006). c) Accommodation type. The type of accommodation selected by the tourist is classified by the literature 
through different categorical variables (Alegre \& Pou, 2006). In particular, our study considers the following four variables: "Bed and Breakfast", "Hotel", "Rented Apartment", "Motel", "Family or Friends' House" and "Campsite". "Bed and Breakfast" is used as the reference category.

\subsection{Data Collection}

Data for this study were collected from visitors to a drive tourism destination on the Atlantic Coast of the United States. It is a major destination located within approximately two hours' driving distance of about 34 million people living in the metropolitan areas of the North East corridor and is popular for natural attractions, sandy beaches, and unique architecture. As part of a two-year effort to better understand destination visitors, paper-based surveys were distributed at three locations: accommodation businesses (e.g., hotels, bed and breakfasts), shops in the tourist areas, and at festivals. This threefold approach ensured to avoid a convenience sample by capturing most destination visitors and allowed collecting data that was of general interest to destination decision makers. A total of 1,484 surveys were collected from Spring 2010 to Spring 2012. This study only includes data from those who indicated that they were visitors to the destination. As a result 908 observations with complete information on the items of interest remained, reflecting a response rate of $61.2 \%$. All of them are US tourists that stay at least one night at the destination.

Travel party members are typically older with about $50 \%$ of them is 51 to 64 years of age, one third is 65 years and older, another third is between the ages of 36 and 50 , and about one quarter is children and teenagers up to 14 years of age. Most travel parties consisted of two members (58.5\%). About one third of travel parties stayed at motels while $28.5 \%$ stayed in hotels and about one quarter in bed and breakfasts. In terms of activities, fine dining was the most popular activity followed by going to the 
beach and shopping. About half of the respondents indicated that they came for history and culture. A small number of respondents indicated that their travel party did not spent any money (3.1\%) during their stay, while about the same number of respondents spent more than $\$ 5,000$. Nearly half of the travel parties spent $\$ 251$ to 1,000 with about another third spending $\$ 1,001$ to 5,000. About $80 \%$ of respondents were repeat visitors. The majority of respondents indicated that they visited the destination more than three times in the past three years; hence they travel to the destination more than once a year (39.8\%). About $20 \%$ visited the destination for the first time. The mean distance travelled is 135 miles.

\section{= TABLE 1 ABOUT HERE =}

\section{RESULTS}

Table 2 presents the results of the effects of distance and first-time visitation on length of stay. Distance and first-time visitation show global significant results $(p<0.1 \%)$ through the likelihood ratio. However, more relevant for this study is the fact that the parameter $\alpha$ is significant at a level of $0.1 \%$. The main implication of this is the invalidation of the basic assumption of mean-variance equality of the Poisson models, which favors the use of the Negative Binomial model (Cameron \& Trivedi, 1998). In other words, it shows the existence of heterogeneity of tourist preferences, which implies the use of a model that allows for its inclusion in order to avoid possible biases in the estimations (Gurmu \& Trivedi, 1996) ${ }^{2}$.

\section{= TABLE 2 ABOUT HERE =}

The result shows that distance has a positive and significant parameter (which is significant at $1 \%$ ), indicating that as distance increases, length of stay increases too;

\footnotetext{
${ }^{2}$ We have tried other distributions, which, despite producing similar results, none of them had a superior fit than the Negative Binomial model. In particular, Poisson (LL=-1497.05), Exponential (LL=-1705.91), Normal (LL=-2208.37).
} 
thus, accepting hypothesis 1 that distance has an effect on length of stay. As the displacement of a tourist entails physical, temporal and financial effort, this effect implies that tourists will visit a long-distance destination if they stay there for a minimum number of days, which compensates for the effort made in the journey and allows them to spread the fixed costs associated with the long journey over a period that is long enough.

First-time visitation has a significant positive effect on length of stay (which is significant at $0.1 \%$ ), indicating that it causes an increment in length of stay. This result confirms the results obtained by Thrane (2012) and explains the variety-seeking behavior among tourists. That is, tourists who are constantly seeking for new experiences might be willing to stay longer to explore a new destination, confirming hypothesis 2 that first-time visits have a positive effect on length of stay.

Relative to the reference category "bed and breakfast", the accommodation types "hotel", "camping", "rented apartment" and "motel" are found to exert greater significant effects on length of stay. However, staying at friends and relatives' homes does not seem to have a different effect from "bed and breakfast". According to the Wald test, "camping" and "rented apartment" have a similar (not significantly different) impact on length of stay $\left(\chi_{1}=0.004 ; \mathrm{p}=0.9469\right)$, which is significantly greater than those of "hotel" $\left(\chi_{1}=6.0613 ; \mathrm{p}=0.0138\right)$ and "motel" $\left(\chi_{1}=8.3968 ; \mathrm{p}=0.003\right)$. As stated, "bed and breakfast" and "friends and relatives" have the lowest effect on duration of stay.

\section{CONCLUSION}

Due to its important managerial implications for tourism, the determinants of length of stay have been largely studied during the last years. However, some dimensions still present ambiguous and contrasting results. Specifically, this study analyzes the effects of distance and first-time visitation on duration of stay at tourism destinations. Through 
Truncated Negative Binomial models, significant positive effects of distance and firsttime visitation on length of stay were identified (supporting Hypotheses 1 and 2), which confirms the results of previous literature (Anderson, 1970; Blaine, Mohammad, \& Var, 1993; Paul \& Rimmawi, 1992; Silberman, 1985; Thrane, 2012). That is, tourists who travel further distances from their places of origin are more inclined to stay longer at the destinations, so as tourists who visit the destinations for the first time. On the account of lack of consensus, these positive effects contradict other outcomes in the literature (Lehto et al., 2004; Alegre \& Pou, 2006; Menezes, Moniz, \& Vieira, 2008; Barros and Machado, 2010).

This study offers an important theoretical implication: the invalidation of the basic assumption of mean-variance equality of the Poisson models favors the use of the Negative Binomial model as it allows modeling the existing heterogeneity of tourist preferences. Also, as this study provides empirical supports for the positive significant effects of distance and first-time visitation, important managerial and marketing implications can be suggested for tourism destinations and firms. The promotion of destinations should be developed with a special attention paid to target faraway markets of origin, due to the marked propensity for these tourists to spend longer periods at the destination. Likewise, market segments that are inclined to explore new destinations rather than revisiting past ones are generally attractive for tourism destinations, as they tend to stay longer. However, irrespective of the promoter, be it the destination itself or the tourism firms at the destination, it is important to consider the type of accommodation that prevails at the destination or the one that its tourists tend to use. It is important to remember that distinct types of accommodation lead to significantly different effects on length of stay. 
For further research, it is important to analyze the application of this model and its research questions in different types of destinations. Specifically, understanding whether these effects take place in rural or urban destinations, beach or mountain destinations, etc. will assist in confirming and reinforcing the relationships found in this study. Furthermore changes in technologies and business models (e.g. low lost airfare or last minute bookings online) affect travel behavior, especially for long-haul destinations. More importantly, it is crucial to find potential distinctive effects among the different types of destinations as it could lead to dissimilar patterns.

Also, two issues that are beyond the goals of this study should be considered: one is methodological and the other is empirical. From a methodological viewpoint, it would be relevant to determine the best method among the existing alternatives (survival models, mixture models, quantile regression, ordered logit models, etc.). Certainly, it should be in the research agenda of the analysis of length of stay. From an empirical standpoint, this article assumes a single decision and its causal relationships thereof. As different trip characteristics are sometimes decided on simultaneously and the order in which tourists decide length of stay, destination, accommodation, etc. is generally unknown, it would be crucial to identify, first, whether tourists follow a sequential decision process in which one or more decisions are made in each stage of the process, and second, to detect which decisions are made in each phase. While theorizing about it is possible, it is not always feasible and most studies leave the issue of sequencing decisions to an empirical question. 


\section{REFERENCES}

Adamowicz, W., Louviere, J. and Williams, M., (1994). Combining revealed and stated preference methods for valuing environmental amenities. Journal of Environmental Economics and Management 26(3), 271-292.

Agarwal, V.B., and Yochum, G.R. (1999). Tourist spending and race of visitors. Journal of Travel Research 38(2), 173-176.

Aissa, S.B. and Goaied, M. (2014). Performance of Tourism Destinations Evidence From Tunisia. Journal of Hospitality \& Tourism Research. Epub ahead of print 24 September 2014.

Alegre, J. and Pou, L., (2006). The length of stay in the demand for tourism. Tourism Management 27(6), 1343-1355.

Alegre, J., and Juaneda, C. (2006). Destination loyalty: Consumers' economic behavior. Annals of Tourism Research 33(3), 684-706.

Alegre, J., Mateo, S., and Pou, L. (2011). A latent class approach to tourists' length of stay, Tourism Management 32(3), 555-563.

Anderson, J.R.L. (1970). The Ulysses Factor (Ed.). New York, NY: Harcourt Brace Johanovich, Inc.

Barros, C.P., and Machado, L.P. (2010). The length of stay in tourism. Annals of Tourism Research 37(3), 692-706.

Barros, C.P., Butler, R., and Correia, A. (2008). Heterogeneity in destination choice: Tourism in Africa. Journal of Travel Research 47(2), 235-246.

Barros, C.P., Butler, R., and Correia, A. (2010). The length of stay of golf tourism: A survival analysis. Tourism Management 31(1), 13-21.

Baxter, M.J. (1980). The interpretation of the distance and attractiveness components in models of recreational trips. Geographical Analysis 11(3), 311-315. 
Beaman, J. (1974). Distance and the 'reaction' to distance as a function of distance. Journal of Leisure Research 6(summer), 220-231.

Beaman, J. (1976). Corrections regarding the impedance of distance functions for several $\mathrm{g}(\mathrm{d})$ functions. Journal of Leisure Research 8(1), 49-52.

Bell, F.W., and Leeworthy, V.R. (1990). Recreational demand by tourists for saltwater beach days. Journal of Environmental Economics and Management, 18, 189-205.

Blaine, T.W., Mohammad, G., and Var, T. (1993). Demand for rural tourism: An exploratory study. Annals of Tourism Research 20(4), 770-773

Borgers, A.W.J., Van Der Heijden, R.E.C.M., and Timmermans, H.J.P. (1989). A variety seeking model of spatial choice-behavior. Environment and Planning A 21(8), 1037-1048.

Cameron, A.C., and Trivedi, P.K. (1998). Regression Analysis of Count Data. New York, NY: Cambridge University Press.

Cannon, T.F., and Ford, J. (2002). Relationship of demographic and trip characteristics to visitor spending: An analysis of sports travel visitors across time. Tourism Economics 8(3), 263-271.

Chintagunta, P.D. (1998). Inertia and variety seeking in a model of brand-purchase timing. Marketing Science 17(3), 153-270.

Correia, A., Silva, J.A. and Moço, C. (2008). Portuguese Charter Tourists to Long-Haul Destinations: A Travel Motive Segmentation. Journal of Hospitality \& Tourism Research 32(2): 169-186.

Fakeye, P.C., and Crompton, J.L. (1991). Image differences between prospective, firsttime, and repeat visitors to the Lower Rio Grande Valley. Journal of Travel Research, 30(Fall), 10-16. 
Ferrer-Rosell, B., Martínez-Garcia, E., Coenders, G. (2014). Package and no-frills air carriers as moderators of length of stay. Tourism Management 42, 114-122.

Fesenmaier, D.R. (1988). Integrating activity patterns into destination choice models. Journal of Leisure Research 20(3), 175-191.

Gokovali, U., Bahar, O., and Kozak, M. (2007). Determinants of length of stay: a practical use of survival analysis', Tourism Management 28(3), pp 736-746.

Greene, W.H. (2008). Econometric Analysis. New York, NY: Prentice Hall.

Grigolon, A.B., Borgers, A.W.J., Kemperman, A.D.A.M and Timmermans, H.J.P. (2014). Vacation length choice: A dynamic mixed multinomial logit model". Tourism Management 41, 158-167.

Gurmu, S., and Trivedi, P.K. (1996). Excess zeros in count models for recreational trips. Journal of Business and Economic Statistics 14(4), 469-477.

Hellerstein, D., and Mendelsohn, R. (1993). A theoretical foundation for count data models. American Journal of Agricultural Economics 75(3), 604-611.

Jang, S, Bai, B., Hu, and Wu, C.-M. (2009). Affect, Travel Motivation, and Travel Intention: a Senior Market". Journal of Hospitality \& Tourism Research 33(1): 5173.

Larsen, J. (2011). Tourism mobilities and the travel glance: Experiences of being on the move. Scandinavian Journal of Hospitality and Tourism 1(2), 80-98.

Lau, L., and McKercher, B. (2004). Exploration versus acquisition: A comparison of first-time and repeat tourists. Journal of Travel Research, 42(3), 279-285.

Lehto, X.Y., Cai, L.A., O’Leary, J.T., and Huan, T.-C. (2004). Tourist shopping preferences and expenditure behaviours: The case of the Taiwanese outbound market. Journal of Vacation Marketing 10(4), 320-332 
Lew, A., and McKercher, B. (2004). Modeling tourist movements: A local destination analysis. Annals of Tourism Research 33(2), 403-423.

Mak, J., and Moncur, J.E.T. (1979). The choice of journey destinations and length of stay: A micro analysis. The Review of Regional Studies 10(2), 38-48.

Mark, David M. (1981). On the positive relation between distance and attractivity in recreation travel: The example of birding. Ontario Geography 17, 83-90.

Martínez-Garcia, E., and Raya, J.M. (2008). Length of stay for low-cost tourism. Tourism Management 29(6), 1064-1075.

Martínez-Garcia, E., and Raya, J.M. (2009). Determinantes de la demanda temporal de turismo: una aproximación macroeconómica con un modelo de duración. Investigaciones Económicas, 33, 271-302.

McKercher, B., Cha, A., and Lam, C., 2008. The impact of distance on international tourist movements. Journal of Travel Research 47(2), 208-224.

Menezes, A.G., Moniz, A., and Vieira, J.C. (2008). The determinants of length of stay of tourists in the Azores. Tourism Economics 14(1), 205-222.

Moutinho, L., and Trimble, J. (1991). A probability of revisitation model: The case of winter visits to the Grand Canyon. The Service Industries Journal 11(4), 439-457.

Nicolau, J., and Más, F. J. (2006). Elección de la duración de las estancias turísticas: una aproximación con modelos de recuento. Revista Europea de Dirección y Economía de la Empresa, 5, 99-115.

Oppermann, M. (1997). First-time and repeat visitors to New Zealand. Tourism Management 18(3), 177-181.

Paul, B.K., and Rimmawi, H.S. (1992). Tourism in Saudi Arabia: Asir National Park. Annals of Tourism Research 19(3), 501-15. 
Perdue, R.R. (1986). Traders and nontraders in recreational destination choice. Journal of Leisure Research 18(1), 12-25.

Prideaux, B., and Carson, D. (2003). A framework for increasing understanding of selfdrive tourism markets. Journal of Vacation Marketing 9(4), 307-313.

Prideaux, B., Wei, S., and Ruys, H. (2001). The senior drive tour market in Australia. Journal of Vacation Marketing 7(3), 209-219.

Pullman, M., and Rodgers, S. (2010). Capacity management for hospitality and tourism: A review of current approaches. International Journal of Hospitality Management 29(1), 177-187.

Raya, J.M. (2012). Length of stay for triathlon participants in the Challenge MaresmeBarcelona: a survival approach. Journal of Sports and Social Issues, 36, 88-104.

Raya, J. M. and Martínez-Garcia, E. (2011). Nationality and low-cost trip duration. A microeconomic analysis. Journal of Air Transport Management, 17, 168-174.

Rittichainuwat, B.N., Qu, H. and Leong. J.K. (2003). The Collective Impacts of a Bundle of Travel Determinants on Repeat Visitation. Journal of Hospitality \& Tourism Research 27(2): 217-236.

Rugg, D. (1973). The choice of journey destination: A theoretical and empirical analysis. The Review of Economics and Statistics 55(1), 64-72.

Salmasi, L., Celidoni, M., and Procidano, I. (2012). Length of stay: price and income semi-elasticities at different destinations in Italy. International Journal of Tourism Research 14(6), 515-530.

Salmasi, L., Celidoni, M., and Procidano, I. (2012). Length of stay: price and income semi-elasticities at different destinations in Italy. International Journal of Tourism Research, 14, 515-530. 
Schroeder, H.W., and Louviere, J. (1999). Stated choice models for predicting the impact of user fees at public recreation sites. Journal of Leisure Research 31(3), $300-324$.

Sharma, S., Durand, R.M., and Gur-Arie, O. (1981). Identification and analysis of moderator variables. Journal of Marketing Research 18(3), 291-300.

Silberman, J. (1985). A demand function for length of stay: The evidence from Virginia Beach. Journal of Travel Research 23(4), 16-23.

Stopher, P.R., and Ergün, G. (1979). Population segmentation in urban recreation choices. Transportation Research 728, 59-65.

Taylor, C.E., and Knudson, D.M. (1976). Area preferences of Midwestern campers. Journal of Leisure Research 7, 39-48.

Thrane, C. (2012). Analyzing tourists' length of stay at destinations with survival models: A constructive critique based on a case study. Tourism Management $33(1), 126-132$.

Tse, P., and Crotts, J.C. (2005). Antecedents of novelty seeking: international visitors' propensity to experiment across Hong Kong's culinary traditions. Tourism Management 26(6), 965-968.

Wang, E., Little, B.B., and DelHomme-Little, B.A. (2012). Factors contributing to tourists' length of stay in Dalian northeastern China - A survival model analysis. Tourism Management Perspectives 4(October), 67-72.

Wang, X.L. (2012). Relationship or revenue: Potential management conflicts between customer relationship management and hotel revenue management. International Journal of Hospitality Management 31(3), 864-874.

Wennergren, E.B., and Nielsen, D.B. (1968). A probabilistic approach to estimating demand for outdoor recreation. Working paper, Utah State University. 
Wolfe, R.I. (1970). Communication. Journal of Leisure Research 2(1), 85-87.

Wolfe, R.I. (1972). The inertia model. Journal of Leisure Research 4(1), 73-76.

Xie, H., Kerstetter, D.L., and Mattila, A.S. (2012). The attributes of a cruise ship that influence the decision making of cruisers and potential cruisers. International Journal of Hospitality Management 31(1), 152-159.

Zillinger, M. (2007). Tourist routes: A time-geographical approach on German cartourists in Sweden. Tourism Geographies 9(1), 64-83. 
Table 1: Travel Party Characteristics, Accommodation Type and Money Spent

\begin{tabular}{|c|c|c|c|}
\hline \multicolumn{2}{|c|}{ Travel party member age groups* } & \multicolumn{2}{|l|}{ Travel party size } \\
\hline Up to 10 years & $14.9 \%$ & Alone & $3.4 \%$ \\
\hline 10 to 14 years & $10.1 \%$ & 2 members & $58.5 \%$ \\
\hline 15 to 21 years & $9.0 \%$ & 3 members & $9.7 \%$ \\
\hline 22 to 35 years & $16.1 \%$ & 4 members & $13.2 \%$ \\
\hline 36 to 50 years & $33.7 \%$ & 5 members & $5.2 \%$ \\
\hline 51 to 64 years & $47.5 \%$ & 6 to 10 members & $6.7 \%$ \\
\hline \multirow[t]{2}{*}{65 years and older } & $32.6 \%$ & 11 to 20 members & $1.9 \%$ \\
\hline & & 21 and more member & $1.4 \%$ \\
\hline Activities* & & Accommodation type* & \\
\hline Fine dining & $83.9 \%$ & Motel & $32.6 \%$ \\
\hline Beaching & $79.5 \%$ & Hotel & $27.0 \%$ \\
\hline Antique shopping & $64.7 \%$ & $\mathrm{~B} \& \mathrm{~B}$ & $24.3 \%$ \\
\hline History/ culture & $48.7 \%$ & Condo rental & $7.9 \%$ \\
\hline Festival & $34.8 \%$ & Family \& Friends & $4.0 \%$ \\
\hline Bird watching & $17.5 \%$ & Campsite/ RV park & $0.6 \%$ \\
\hline Fishing/ boating & $7.7 \%$ & & \\
\hline \multicolumn{2}{|l|}{ Money spent during stay } & \multicolumn{2}{|l|}{ Past Visitation in the past 3 years } \\
\hline None & $3.1 \%$ & Once & $4.3 \%$ \\
\hline$\$ 1$ to 250 & $12.9 \%$ & Second visit & $11.8 \%$ \\
\hline$\$ 251$ to 1,000 & $47.0 \%$ & Third visit & $16.3 \%$ \\
\hline$\$ 1,001$ to 5,000 & $33.8 \%$ & More than three visits & $39.8 \%$ \\
\hline \multirow[t]{2}{*}{$\$ 5,001$ and more } & $3.2 \%$ & Last visit is more than 3 years ago & $7.1 \%$ \\
\hline & & First visit ever & $20.6 \%$ \\
\hline
\end{tabular}

Note: * Indicates questions with "Select All That Apply" answer options. For all N=906. 
Table 2. Effects of distance and novelty on length of stay

\begin{tabular}{lcc}
\hline \hline Variables & Coefficient & SD \\
\hline Distance (thousands of miles) & $0.1418^{\mathrm{b}}$ & 0.0564 \\
First-time visitation & $0.0421^{\mathrm{a}}$ & 0.0131 \\
Hotel & $0.3174^{\mathrm{a}}$ & 0.0559 \\
Rented Apt & $0.8390^{\mathrm{a}}$ & 0.0681 \\
Motel & $0.2294^{\mathrm{a}}$ & 0.0538 \\
Friends \& Relatives & 0.1372 & 0.1130 \\
Campsite & $0.8251^{\mathrm{a}}$ & 0.2078 \\
\hline Constant & $0.9270^{\mathrm{a}}$ & 0.0561 \\
$\alpha$ & $-4.1135^{\mathrm{a}}$ & 0.7824 \\
\hline R-squared & 0.2167 \\
Adjusted R-squared & 0.2082 \\
Log likelihood & -1496.1370 \\
Akaike information criterion & 4.0734 \\
Schwarz information criterion & 4.1295 \\
LR stat & \multicolumn{2}{c}{$198.15^{\mathrm{a}}$} \\
\hline \hline a=prob<0,1\%; b=prob< $<$ \% Dependent Variable - length of stay in number of nights.
\end{tabular}

